\title{
BURCH-SCHNEIDER CAGE FRACTURE: A CASE REPORT
}

\author{
Jiří Gallo* ${ }^{\mathrm{a} *}$ Anthony V. Florschutz ${ }^{\mathrm{b}}$ \\ a Department of Orthopaedics, Teaching Hospital, Palacký University, I.P. Pavlova 6, 775 20, Olomouc, Czech Republic \\ ${ }^{b}$ Currently affiliated with Mayo Clinic, Rochester, MN, USA \\ e-mail: jiri.gallo@volny.cz
}

Received: September 21, 2005; Accepted (with revisions): November 15, 2005

Key words: Burch-Schneider anti-protrusio cage/Fracture/Revision hip arthroplasty/Fatigue failure/Balgrist cup

In this report, we present the case of a 64-year-old woman who sustained a Burch-Schneider cage fracture. Prior to this event, she underwent repeated acetabular reconstructions, but in the end prosthesis removal was performed as a salvage procedure. We believe that the primary cause of the fracture was metal fatigue facilitated by intraoperative re-contouring of the flange, as well as reuse of the cage. Based on this case we caution against repetitive or excessive flange bending during implantation of Burch-Schneider cages and do not recommend their reuse.

\section{INTRODUCTION}

Acetabular cup failure is a persistently encountered complication of total hip arthroplasty (THA) despite the overall exceptional results. ${ }^{1,2}$ Indications for acetabular revision include aseptic loosening of the cup, polyethylene wear, osteolysis, periprosthetic infection, and dislocation. ${ }^{3,4}$ One of the main challenges during revision arthroplasty is to establish rigid cup fixation in an acetabulum that often has damaged and deficient bone. To solve this problem, methods using large porous-coated acetabular cups, bone grafting, and reconstructive cages have all proven to be effective treatment options. ${ }^{5,6}$ Although most acetabular revisions do not require reconstructive cages, a small number of patients with severe combined defects may be best treated by this technique in combination with bone grafting. $5,7-11$

The Burch-Schneider anti-protrusio cage is designed to manage severe combined acetabular defects by bridging large bone gaps and preventing medial and superior cup migration. ${ }^{5,8,12}$ The cage is made of a titanium alloy (Protasul $^{\text {Th }} \mathrm{Ti}$ ) and consists of a hemispherical basket with superior and inferior flanges for iliac and ischial support, respectively. During intraoperative placement, manual bending of the flanges is required to adjust pelvic fit and improves cage support via the ilium and ischium. Screws placed through holes in the cage dome and flanges further secure the cage to the bony pelvis. As an alternative to securing the inferior flange with screws, insertion of the flange into a prepared ischial slot is also an effective cagepelvis binding technique. ${ }^{5,7}$ Defects behind or around the cage are filled with bone graft, and an acetabular cup is cemented into the basket of the cage.

We have been using the Burch-Schneider cage since 1997 to reconstruct severe acetabular bone defects in select patients with satisfactory results. Several complications for this method have been described including aseptic and septic failure, dislocation, migration, neurovascular damage, screw breakage, and others. ${ }^{7,9,10,13-18}$ Cage fracture is a rarely encountered complication and in the available literature we have identified only three cases. ${ }^{7,17}$ The aim of the present report is to describe our experience with this unique complication and review the literature.

\section{CASE DESCRIPTION}

A 58-year-old woman presented to our orthopaedic department in February of 1997 with a history of bilateral postdysplastic osteoarthritis of the hip. She subsequently underwent THA of the right hip using a Balgrist cup (Allopro, Sulzer Medica, Switzerland) and an Alloclassic SL stem (Allopro, Sulzer Medica). There were no complications intraoperatively, during recovery, or at followup.

In September of 1997, due to progressively increasing left hip pain and x-ray evidence of osteoarthritis, the woman elected to undergo THA at our department. During this procedure, a Balgrist cup was placed into the dysplastic acetabulum and an Alloclassic SL stem was implanted as the femoral component. Two weeks later shortening of the left leg was evident on examination, and x-rays of the left hip demonstrated cup protrusion and rotation. During revision surgery, defects of both the anterior and central acetabular regions were reconstructed using bone autograft harvested from the left iliac crest. The failed prosthetic cup was exchanged for a larger Balgrist cup placed more medially to improve host bone coverage. In March of 1998, the woman was asymptomatic and satisfied with her THA outcome, but x-ray showed mild cranial and medial migration of the implanted cup.

At a follow-up examination in April of 2000, x-rays of the left hip revealed a fractured Balgrist cup (Fig. 1). 


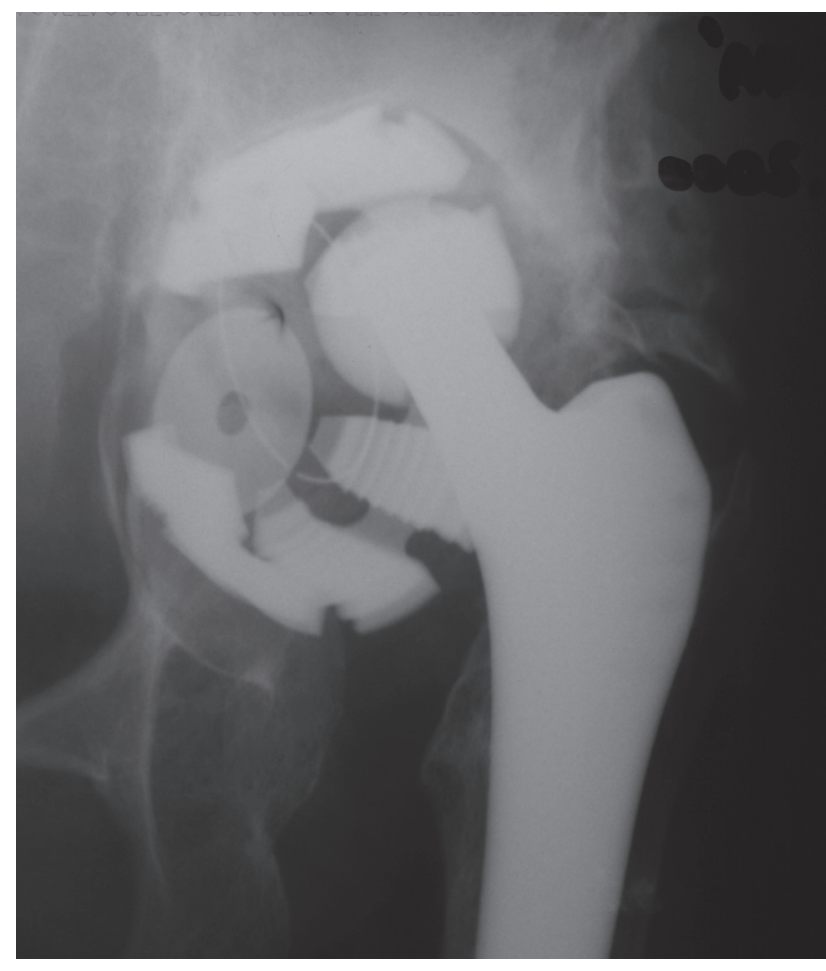

Fig. 1. Radiograph of a fractured Balgrist cup in a 61-yearold woman two and a half years after implantation.

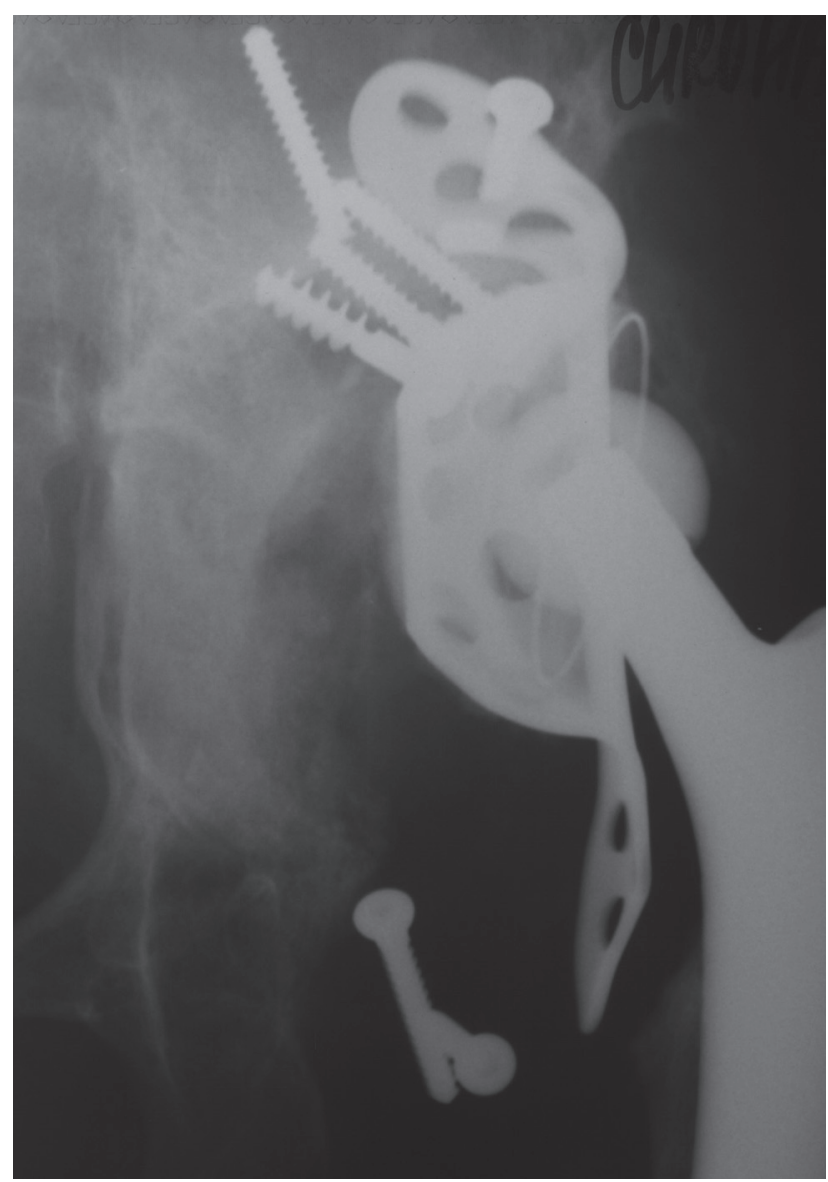

Fig. 3. Radiograph of complete displacement of the BurchSchneider cage one year after cage placement.

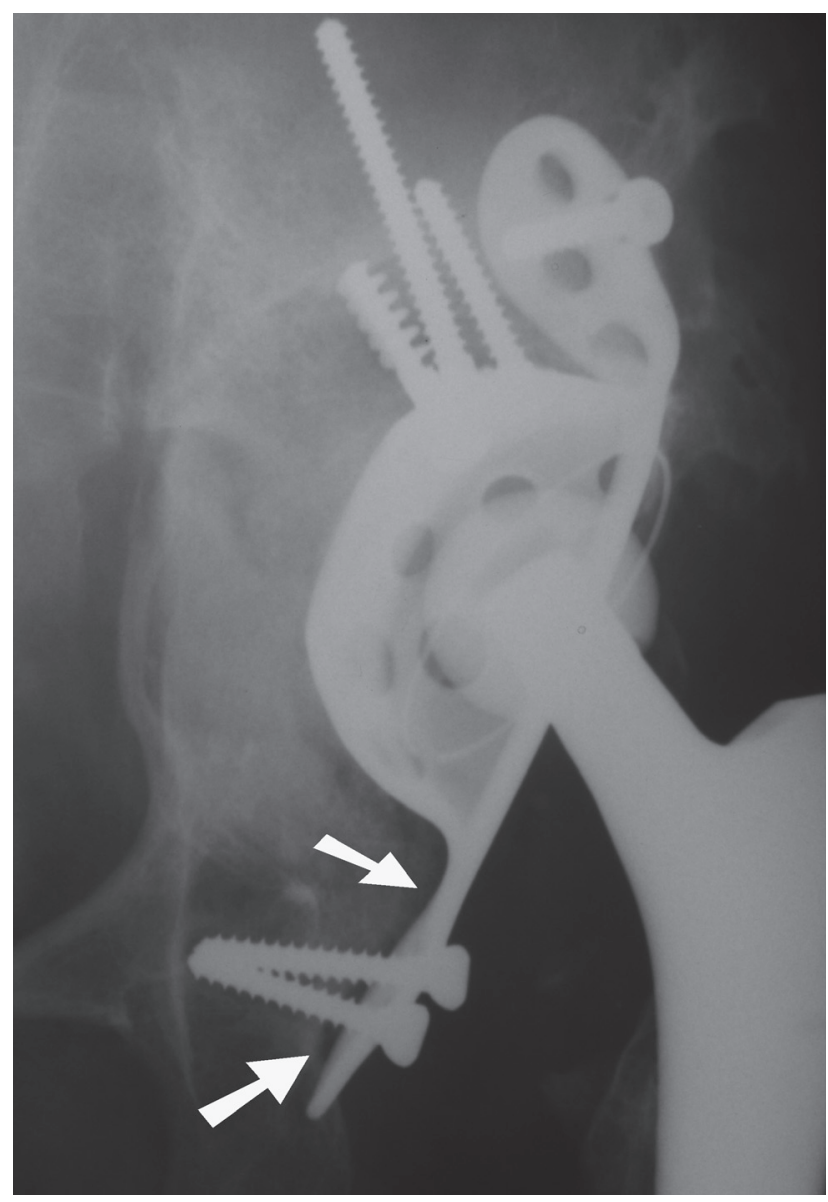

Fig. 2. Radiograph showing the first signs of cage lateralization (arrows) and screw failure 6 months after cage placement.

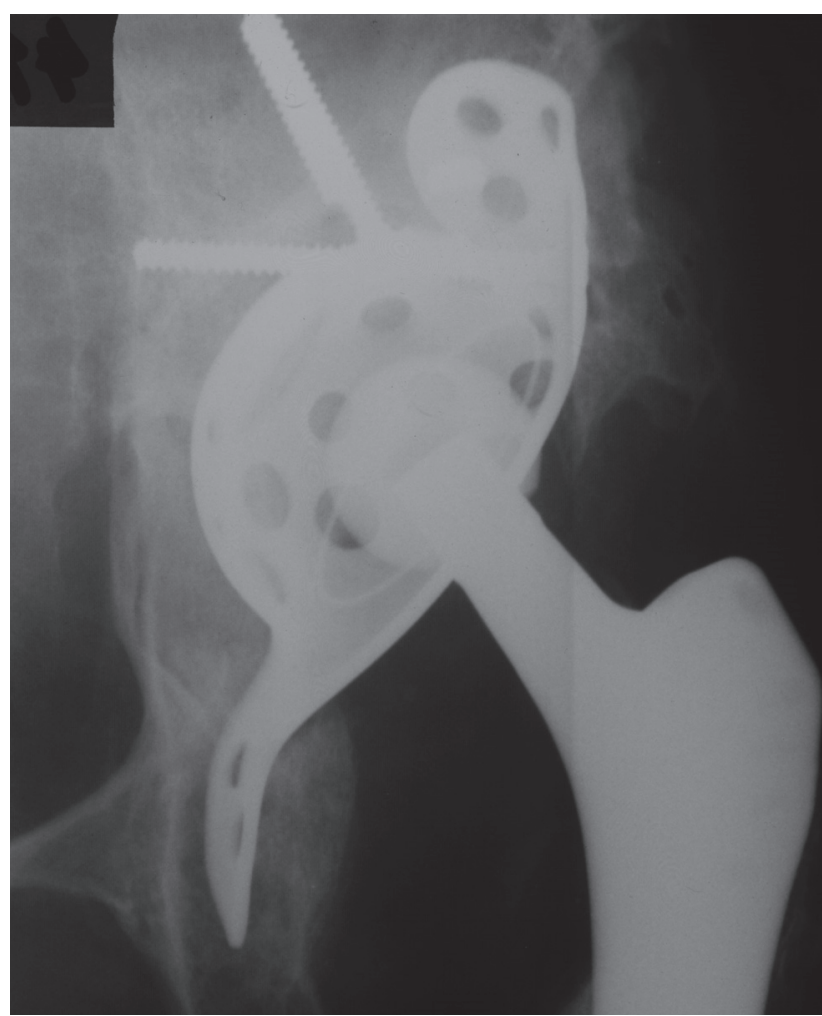

Fig. 4. Postoperative $x$-ray after re-implantation of the Burch-Schneider cage. 


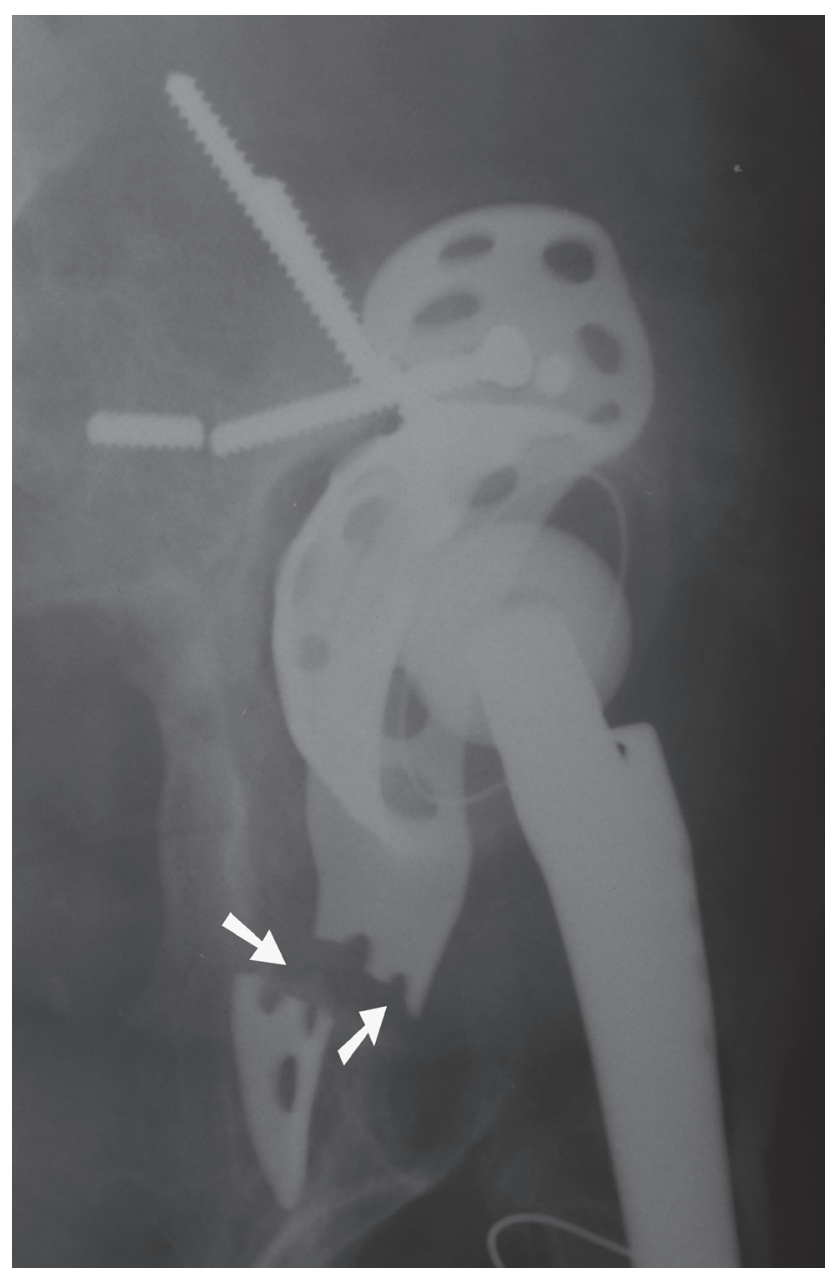

Fig. 5. Oblique radiograph of the fractured Burch-Schneider cage 12 months after revision surgery showing the fracture line (arrows) through the two holes in the inferior flange.

At revision, the bony acetabulum was reconstructed using a structural allograft fastened via a screw to the residual host bone, followed by filling remaining defects with morselized allograft. To bridge the reconstruction, a $50 \mathrm{~mm}$ Burch-Schneider cage (Sulzer Medica, Switzerland) was implanted and secured with cortical screws. An Ultima Semicaptive cup (Johnson \& Johnson, USA) was cemented into the cage basket. Six months later the woman was asymptomatic and walking with crutches. However, the first signs of ischial screw loosening and lateral cage displacement were apparent on X-ray (Fig. 2).

At a routine follow-up one year later, $x$-rays showed massive lateral and cranial migration of the cage and a broken superior flange screw (Fig. 3). The reconstruction involved extensive morselized bone allografting as well as re-bridging of the defect using the same $50 \mathrm{~mm}$ Burch-Schneider cage implanted in the previous revision. To prevent repeated lateral displacement, the inferior flange was slightly re-contoured and inserted into the ischium. This was followed by cementing a new cup into the cage. Postoperative $\mathrm{x}$-ray seemed to show promising integrity (Fig. 4). During a follow-up visit in January of 2002, the passive range of motion of the left hip was $0-80^{\circ}$ flexion and $30^{\circ}$ abduction. Actively, the patient demonstrated abductor insufficiency.

Two months later, x-rays revealed an inferior flange fracture of the Burch-Schneider cage and cranial migration of the entire implant (Fig. 5). The woman had minor symptomatic complaints and was aware of progressive shortening of the left leg. In January of 2003, the prosthesis was completely extracted and the defects were filled with morselized allograft. At a follow-up visit eighteen months later, the woman was pain free, walking with crutches, and independent.

\section{DISCUSSION}

The Burch-Schneider anti-protrusio cage is an effective option for acetabular reconstruction when severe combined acetabular defects are present and a mechanically stable environment cannot be established by other fixation methods. ${ }^{5,7,8,11}$ Complications associated with the technically demanding anti-protrusio acetabular reconstruction cages have been recognized by other authors. ${ }^{7,9,10,13-17}$

Gill et al. reported an overall 19 percent complication rate at an average follow-up of 8.5 years in a group of 63 hip revisions using a Burch-Schneider cage. ${ }^{16}$ However, none of the complications reported were due to cage fracture. Goodman et al. evaluated 42 Burch-Schneider cages and 19 Contour rings (Smith and Nephew Richards, Memphis, $\mathrm{TN}$ ) and found that only $44 \%$ (27/61) were complication free after a mean of 4.6 years postoperatively. ${ }^{7}$ Among the complications, one Burch-Schneider cage inferior flange fracture $(2.4 \%$; 1 of 42$)$ was described in an older patient with ankylosing spondylitis and larger acetabular defects (AAOS Type III, Gross Type IV) requiring structural allografting. Time to failure was two years. Perka and Ludwig also mentioned two instances of Burch-Schneider cage fracture occurring as late complications $(3.2 \%$; 2 of 63 ) but no details were reported. ${ }^{17}$

When the Burch-Schneider cage was initially implanted in our patient, the residual acetabulum was reconstructed using structural and morselized bone allografts, and the inferior cage flange was slightly bent to follow the ischial contour with minimal discrepancies. This strategy requires a pliable yet strong cage material, a solid bone bed for cage support, and effective screw placement. We suspect that the first cage failure with lateralization in our patient might be due to suboptimal establishment of the latter two criteria.

During the following revision, the retrieved cage was deemed intact and without signs of structural compromise and thus seemed adequate for reuse. The inferior flange was alternatively inserted into an ischial slot to prevent lateral cage displacement, requiring a different flange angle, i.e. re-contouring in a slightly reverse direction than previously. Although failure due to re-contouring has not been studied with this device, we believe that this re-bending may be the cause of the inferior flange fracture. This mechanism conforms to basic engineering experience that 
repetitive deformation can fatigue metal. Additionally, the level of the two holes in the inferior flange may be an area more prone to fatigue (and fracture) since resistance to bending is less at that point and there is the potential for screw-inflicted damage.

The relationship between extensive bone defects and early cage failure in our patient seems to be supported by various studies. ${ }^{72-15}$ Udomkiat et al. noted a strong association between the incidence of metal reinforcement loosening and the degree of superior acetabular bone defects. ${ }^{8}$ Perka and Ludwig reported Burch-Schneider cage migration in all patients with Paprosky IIIb defects and severe posterior column compromise. ${ }^{17}$ Similar findings were published by Peters et al. and others. ${ }^{7,10,19}$ Conversely, van Koeveringe and Ochsner did not find any correlation between the extent of acetabular defects and cage migration. ${ }^{18}$

Surprisingly, our patient suffered only minor complaints in spite of gross cage migration (Fig. 2 and 5). Perka and Ludwig noted similar occurrences, finding a poor correspondence between migration and clinical symptoms. ${ }^{17}$ This discrepancy between early prosthetic failure and clinical presentation has been recognized for some time. ${ }^{20}$ However, it has been our experience that the gross prosthetic migration occurring in our patient typically presents with a more urgent clinical picture.

The Burch-Schneider cage is a very useful and effective device for managing select patients with severe acetabular defects. Our patient represents a unique case of cage fracture occurring as an early complication. To date there have been no reports on whether cage reuse or repetitive bending increases the risk of cage failure or specifically inferior flange fracture. We strongly caution against Burch-Schneider cage reuse and repetitive flange bending during cage implantation as these practices may lead to structural cage failure.

\section{ACKNOWLEDGEMENT}

The authors wish to thank Ms. Jarmila Potomkova and Mark J. Spangehl, MD for helpful editorial work.

\section{REFERENCES}

1. Callaghan JJ, Albright JC, Goetz DD, Olejniczak, JP, Johnston, RC. (2000) Charnley total hip arthroplasty with cement. Minimum twenty-five-year follow-up. J Bone Joint Surg 82A, 487-97.

2. Della Valle CJ, Berger RA, Shott S, Rosenberg AA, Jacobs JJ, Quigley L, Galante JO. (2004) Primary total hip arthroplasty with a porous-coated acetabular component. A concise follow-up of a previous report. J Bone Joint Surg 86A, 1217-22.

3. Malchau H, Herberts P, Eisler T, Garellick G, Soderman P. (2002) The Swedish Total Hip Replacement Register. J Bone Joint Surg 84A Suppl.2, 2-20.

4. Wroblewski BM, Siney PD, Fleming PA. (2002) Charnley lowfrictional torque arthroplasty in patients under the age of 51 years. Follow-up to 33 years. J Bone Joint Surg 84B, 540-43.

5. Berry DJ. (2004) Antiprotrusio cages for acetabular revision. Clin Orthop 420, 106-12.

6. Whaley AL, Berry DJ, Harmsen WS. (2001) Extra-large uncemented hemispherical acetabular components for revision total hip arthroplasty. J Bone Joint Surg 83A, 1352-57.

7. Goodman S, Saastamoinen H, Shasha N, Gross A. (2004) Complications of ilioischial reconstruction rings in revision total hip arthroplasty. J Arthroplasty 19, 436-46.

8. Udomkiat P, Dorr LD, Won YY, Longjohn D, Wan Z. (2001) Technical factors for success with metal ring acetabular reconstruction. J Arthroplasty 16, 961-69.

9. Wachtl SW, Jung M, Jakob RP, Gautier E. (2000) The BurchSchneider antiprotrusio cage in acetabular revision surgery: a mean follow-up of 12 years. J Arthroplasty 15, 959-63.

10. Winter E, Piert M, Volkmann R, Maurer F, Eingartner C, Weise K, Weller S. (2001) Allogeneic cancellous bone graft and a BurchSchneider ring for acetabular reconstruction in revision hip arthroplasty. J Bone Joint Surg 83A, 862-67.

11. Rozkydal Z, Sklensky M. (1999) Burch-Schneider ring in revision surgery of THR. Acta Chir Orthop Traumatol Cech 66, 176-80.

12. Rosson J, Schatzker J. (1992) The use of reinforcement rings to reconstruct deficient acetabula. J Bone Joint Surg 74B, 716-20.

13. Berry DJ, Lewallen DG, Hanssen AD, Cabanela ME. (1999) Pelvic discontinuity in revision total hip arthroplasty. J Bone Joint Surg 81A, 1692-1702.

14. Berry DJ, Muller ME. (1992) Revision arthroplasty using an antiprotrusio cage for massive acetabular bone deficiency. J Bone Joint Surg 74B, 711-15.

15. Bohm P, Banzhaf S. (1999) Acetabular revision with allograft bone. 103 revisions with 3 reconstruction alternatives, followed for 0.3-13 years. Acta Orthop Scand 70, 240-49.

16. Gill TJ, Sledge JB, Muller ME. (1998) The Burch-Schneider antiprotrusio cage in revision total hip arthroplasty: indications, principles and long-term results. J Bone Joint Surg 80B, 946-53.

17. Perka C, Ludwig R. (2001) Reconstruction of segmental defects during revision procedures of the acetabulum with the BurchSchneider anti-protrusio cage. J Arthroplasty 16, 568-74.

18. van Koeveringe AJ, Ochsner PE. (2002) Revision cup arthroplasty using Burch-Schneider anti-protrusio cage. Int Orthop 26, 29195.

19. Peters CL, Curtain M, Samuelson KM. (1995) Acetabular revision with the Burch-Schneider antiprotrusio cage and cancellous allograft bone. J Arthroplasty 10, 307-12.

20. Amstutz HC, Ma SM, Jinnah RH, Mai L. (1982) Revision of aseptic loose total hip arthroplasties. Clin Orthop 170, 21-33. 